\title{
Cocoa consumption and blood pressure: a systematic review
}

\begin{abstract}
Chocolate is a highly popular food item in Western societies. However, there has been heavy criticism regarding chocolate consumption due to its high sugar and fat content, as well as its "addictive" nature. Persons can consume well over the suggested serving size for chocolate without being conscious of the fact. Researchers have attempted to find some positive characteristics of chocolate, so as to teach the public how to best consume this food while gaining some health benefits. In recentyears, chocolate has been associated with lowering blood pressure as well as other beneficial side effects associated with heart disease. The following is a systematic review of recent articles and studies, which aim to show the association between chocolate consumption and various health risks and benefits related to cardiovascular disease. The results of these studies vary but overwhelmingly support the finding that chocolate consumption has beneficial effects on blood pressure, vasodilation, and other factors related to cardiovascular disease.
\end{abstract}

Keywords: cocoa consumption, systematic review, cardiovascular diseases
Volume 2 Issue 3 - 2015

Tveen Tcharkhoutian
Loma Linda University, USA

Correspondence: Tveen Tcharkhoutian, Loma Linda University, 3325 Paloma St. Pasadena, CA, 9 I I07, Tel (626) 4195294,Email tveent@gmail.com

Received: March 26, 2015 | Published: April 24, 2015

\section{Introduction}

Cardiovascular disease and its associated risks have risen in prevalence over the past few decades, especially in the United States. According to the Center for Disease Control (CDC) review in 2011, $30 \%$ of adults in the United States currently suffer from cardiovascular disease. Additionally, heart disease and stroke accounted for over $33.6 \%$ of all deaths in $2011 . .^{1}$ These astounding statistics call for more research to be done on this disease and for ways to raise the public's awareness. Some risk factors associated with cardiovascular disease include blood pressure, high cholesterol, and insulin resistance. ${ }^{2}$

For years, cocoa and chocolate have been popular food items across the United States and essentially around the world. The benefits of cocoa were first discovered by the Aztecs who considered it a "divine drink"(3). However, cocoa has been taken out of its natural form and has undergone processing with sugar and sometimes milk, which is more correctly termed "chocolate". ${ }^{3}$ The benefits of this type of chocolate have been thought to be slim, considering its high sugar and fat content. However, recent studies have shown a relationship between cocoa consumption and reduced risk of cardiovascular disease. ${ }^{4}$ These studies have brought about the popularity of dark chocolate and cocoa products, which contain the beneficial polyphenols and flavanols, which have antioxidant qualities. ${ }^{5}$ Chocolate seems to have a role in lowering blood pressure and increasing vasodilation. ${ }^{6}$ The flavonoids in dark chocolate have been seen to activate the nitric oxide synthase system (which aids in vasodilation), contain antioxidant properties, and decrease blood clotting by inhibiting platelet activation aggravation. These functions all contribute to the decrease in blood pressure and a resulting decrease in the risk of developing cardiovascular disease.

A variety of tests were done in the following reviewed studies in order to measure blood pressure, endothelial function, and overall vascular health. Along with measuring systolic and diastolic blood pressure, researchers also measured endothelial function, which refers to arterial vasomotor responses, which are mediated by nitric oxide (NO), a vasodilator, and endothelin, a vasoconstrictor. ${ }^{7}$ Researchers also measured nitric oxide levels expression, concluding that higher levels relieved endothelial dysfunction and had to potential to reduce blood pressure. Other risk factors associated with cardiovascular disease, including glucose levels and serum cholesterol, were also measured via oral glucose tolerance tests and blood tests respectively. ${ }^{8}$

Many studies have been done in the recentyears, and these findings will be reviewed and analyzed in this paper.

\section{Methods}

Search engines, such as EBSCO, PubMed, and Google Scholar, were employed to conduct a thorough evaluation of the current literature regarding cocoa consumption and blood pressure. The dates searched were between 2005-2012. Key words such as "cocoa", "chocolate", "blood pressure", and "cardiovascular disease" were used to obtain the discussed studies in this systematic review. Only articles written and clinical trials conducted after 2002 were utilized in the research for this paper. The results of this search yielded five randomized clinical trials, two longitudinal studies, and four reviews and meta-analyses.

\section{Discussion}

\section{Randomized clinical trials}

Many randomized clinical trials have been conducted to see the effects of cocoa on blood pressure and various other measurements pertaining to vasodilation and overall cardiac health. The earliest two randomized clinical trials reviewed were both conducted by Grassi ${ }^{8}$ and various teams in 2005. Grassi et al., ${ }^{8}$ examined the effects of a short-term administration of dark chocolate to healthy individuals and its effects on their blood pressure and insulin response using an oral glucose tolerance test. The subjects consisted of 15 healthy subjects with a mean age of 34 and randomly placed in groups to consume a dark chocolate or white chocolate bar, and then were crossed over to the other group after a seven-day wash out phase. The results showed a significant decrease in insulin resistance as well as a significant reduction in systolic and diastolic blood pressures after the consumption of dark chocolate, but not white chocolate. 
Grassi et al., ${ }^{8}$ conducted another study in 2005 evaluating the effects of cocoa on blood pressure more closely. This study consisted of 20 individuals with essential hypertension, defined as blood pressure levels between $140 / 90$ and $160 / 100 \mathrm{mmHg}$ or greater on four consecutive visits performed at one-week intervals. There was a control group of 15 individuals that were normotensive with blood pressure levels less than $130 / 85 \mathrm{mmHg}$. The results of this study showed that consumption of dark chocolate reduced daytime and nighttime blood pressure, reduced insulin resistance, and improved NO-dependent vasorelaxation. ${ }^{9}$

Grassi et al., ${ }^{8}$ conducted a third study more recently in 2008 measuring the effects of consuming chocolate over a fifteen-day period on glucose-intolerant hypertensives. The aim of this study was to measure the effects of chocolate on blood pressure as well as various measurements pertaining to vasodilation and glucose tolerance. The nineteen subjects were randomly assigned to consume a dark or white chocolate bar, then switched over in this single crossover randomized clinical trial to the other chocolate bar after the designated wash out period. Results showed similar results compared to the 2005 studies, with the participants experience increased insulin sensitivity, decreased blood pressure, and increased flow mediated dilation. This study also examined serum cholesterol levels and resulted in a decreased in total and LDL cholesterol. ${ }^{6}$ The Grassi studies all show that a flavanol rich diet, even if the source is from dark chocolate, is beneficial in reducing blood pressure and improving insulin sensitivity.

Taubert et al., ${ }^{10}$ conducted a clinical trial in 2007, which aimed at assessing the affects of low habitual cocoa intake and blood pressure. This randomized study consisted of 44 adults aged 56-73 with prehypertension or stage 1 hypertension that have not been treated. Participants were randomly placed in two groups: one received polyphenol-rich dark chocolate (only 30k calories) while the other received polyphenol-free white chocolate, both at equal amounts. The results showed decreased systolic and diastolic blood pressures among the participants consuming the polyphenol-rich dark chocolate, as well as a decrease in hypertension prevalence among this group as well. There was also a significant increase of nitric oxide presence in this group, which assumes vasodilation of the arteries and overall decrease of blood pressure. Furthermore, the group consuming white chocolate did not experience any of the beneficial results on their blood pressure of nitric oxide levels, illustrating yet again the health benefits associated with an even low intake of dark chocolate. ${ }^{10}$

In 2008, Faridi et al., ${ }^{7}$ conducted a single blind crossover trial to evaluate the acute or immediate affects on the consumption of dark chocolate verses placebo bars, as well as sugar free and sugared cocoa bars. Results showed that the solid dark chocolate and the liquid cocoa both had significant beneficial effects in improving endothelial function compared with the other substances consumed. Interestingly, endothelial function improved more significantly with the sugarfree cocoa liquid compared to the sugared cocoa liquid. Systolic and diastolic blood pressures were also reduced with the consumption of the dark chocolate bar as well as the sugar free cocoa liquid. ${ }^{7}$ These findings, along with the three previous randomized clinical trial results, illustrate the benefits of dark chocolate consumption on blood pressure and endothelial function.

\section{Observational studies}

Two observational studies were evaluated while conducting this systematic review, both completed by Buijsse et al., ${ }^{11}$ and two respective teams. The first was a prospective cohort study, conducted in 2006 by Buijsse et al., ${ }^{11}$ which aimed to evaluate the connection between habitual cocoa intake and blood pressure and whether or not this prospectively affected cardiovascular mortality. A cohort of 470 elderly men free of chronic diseases was used for baseline data. Blood pressure was initially measured, then collected again after five years, after which causes of death were obtained during a 15-year follow up period. Dietary records were evaluated during this period and cocoa consumption was analyzed using these food records. Results showed an inverse association between cocoa intake and blood pressure as well as a $45-50 \%$ decreased risk of cardiovascular and all-cause death. ${ }^{11}$

The second observational study was also a prospective cohort, conducted from 1994 through 2010 by Buijsse et al., ${ }^{12}$ evaluating the relationship between chocolate consumption, blood pressure, and the incidence of myocardial infarctions and strokes. A large cohort of 27,548 participants was followed. Baseline data and measurements, such as food frequency questionnaires and blood pressure, were gathered between 1994 and 1998, and systematic follow up session were conducted every 2-3years through the year 2006. Participants were placed in quartiles related to their cocoa consumption and results showed a reduced systolic and diastolic blood pressure among the top quartile compared to the bottom quartile of chocolate consumers, showing an association between chocolate consumption and lower blood pressure. There was also an inverse association between chocolate consumption and the incidence of myocardial infarction or stroke, a stronger association occurring for stroke incidence. Baseline blood pressure explained $12 \%$ of this overall lower risk of myocardial infarction and stroke. This suggests that chocolate consumption decreases blood pressure and has a protective effect against the incidence of myocardial infarctions and strokes (Table 1). ${ }^{12}$

\section{Conclusion}

Cardiovascular disease is one of the leading causes of death in the United States. ${ }^{1}$ Research examining ways in which to reduce risk factors associated with heart disease are of vital importance for our population. The benefits of consuming dark chocolate on cardiovascular health has been widely proven as is evident in the reviewed randomized clinical trials. These interventions illustrated a decrease in systolic and diastolic blood pressures, improved endothelial function, increased nitric oxide expression, and increased insulin sensitivity in the participants consuming dark chocolate. Considering the popularity of chocolate as a food item, it is important to continue researching the nutrients in chocolate and their beneficial affects on overall health and well-being.

\section{Application to public health}

As public health and nutrition professionals, it is vital to present data and make recommendations based on this research in a way that will be best received by the general public, as well as best adhered to. Concerning the benefits of cocoa, there is a fine line between making a positive health claim and supporting the consumption of chocolate and leading the public astray. It is important to note that many of these studies educated the participants on how to replace their overall caloric intake with the chocolate bar so as to not increase their overall energy intake. ${ }^{9}$ Furthermore, the Taubert ${ }^{10}$ study in 2007 illustrated that a small portion of cocoa was beneficial by administering only $30 \mathrm{k}$ calories per day to its participants. Advertising the benefits of cocoa consumption could affect cardiovascular disease rates by decreasing 
risk factors, as was seen with many of these clinical trials. However, it is important to also educate the public on the correct type (cocoa and not white or milk chocolate), the correct portion, and the correct number of calories of cocoa to consume in order to gain these health benefits.

Table I Relationship between Cocoa Consumption and Blood Pressure

Authors $\begin{aligned} & \text { Subjects and } \\ & \text { study design }\end{aligned} \quad$ Target $\quad$ Outcome

\section{Observational studies}

\begin{tabular}{|c|c|c|c|}
\hline $\begin{array}{l}\text { Buijsse et } \\
\text { al." }\end{array}$ & $\begin{array}{l}\text { Prospective cohort } \\
\mathrm{N}=470\end{array}$ & $\begin{array}{l}\text { Habitual cocoa intake, BP, and } \\
\text { cardiovascular mortality }\end{array}$ & $\begin{array}{l}\text { Inverse association between cocoa intake and blood pressure } \\
45-50 \% \text { decreased risk of cardiovascular and all-cause mortality associated } \\
\text { with cocoa consumption }\end{array}$ \\
\hline $\begin{array}{l}\text { Buijsse et } \\
\text { al. }^{\prime 2}\end{array}$ & $\begin{array}{l}\text { Prospective cohort } \\
\mathrm{N}=27,548\end{array}$ & $\begin{array}{l}\text { Chocolate consumption, BP, MI, and } \\
\text { stroke }\end{array}$ & $\begin{array}{l}\text { Reduced systolic and diastolic BP among participants consuming more } \\
\text { chocolate } \\
\text { Inverse association between chocolate consumption and incidence of MI } \\
\text { and stroke (stronger association for decreased incidence of stroke) } \\
\text { RR for combined outcome of } \mathrm{MI} \text { and stroke }(0.6 \mathrm{I}, \mathrm{p} \text { linear trend }=0.0 \mathrm{I} 4)\end{array}$ \\
\hline
\end{tabular}

\section{Randomized Clinical Trials}

\begin{tabular}{|c|c|c|c|}
\hline $\begin{array}{l}\text { Grassi } \\
\text { et al. }{ }^{8}\end{array}$ & $\begin{array}{l}\text { Single blind } \\
\text { crossover } \\
\mathrm{N}=15 \text {, mean age } 34\end{array}$ & $\begin{array}{l}\text { Short term DC consumption, IS, } \\
\text { and BP }\end{array}$ & $\begin{array}{l}\text { Lowered IR using HOMA-IR }(0.94+/-0.42 \text { compared with WC }(\mathrm{I} .72+/- \\
0.62, \mathrm{p}<0.00 \mathrm{I}) \\
\text { Lower systolic with DC }(107.5+/-8.6 \mathrm{mmHg}) \text { compared with WC (I I } 3.9 \\
+/-8.4 \mathrm{mmHg}, \mathrm{p}>0.05)\end{array}$ \\
\hline Grassi et al. ${ }^{9}$ & $\begin{array}{l}\text { Single blind } \\
\text { crossover } \\
\mathrm{N}=20 \text {, mean age } 44\end{array}$ & $\begin{array}{l}\text { Cocoa, BP, IR, endothelium- } \\
\text { dependent vasodilation }\end{array}$ & $\begin{array}{l}\text { With DC: } \\
\text { Decreased systolic }(-I I .9+/-7.7 \mathrm{mmHg}, \mathrm{p}<0.00 \mathrm{I}) \text { and diastolic }(-8.5+/- \\
5.0 \mathrm{mmHg}, \mathrm{p}<0.00 \mathrm{I}) \\
\text { Decreased IR using HOMA-IR }(\mathrm{p}<0.00 \mathrm{I}) \text { Improved flow-mediated dilation } \\
(I \mathrm{I} .3+/-1.3 \%, \mathrm{p}<0.00 \mathrm{I})\end{array}$ \\
\hline Grassi et al. ${ }^{6}$ & $\begin{array}{l}\text { Single blind } \\
\text { crossover } \\
N=19 \text {, mean age } 45\end{array}$ & $\begin{array}{l}\text { BP, IS and cocoa consumption for } \\
\text { I } 5 \text { days }\end{array}$ & $\begin{array}{l}\text { With DC: } \\
\text { Decreased systolic }(-3.82+/-2.4 \mathrm{mmHg}, \mathrm{P}<0.00 \mathrm{I}) \text { and diastolic } \mathrm{BP}(-3.92 \\
+/-1.98 \mathrm{mmHg}, \mathrm{P}<0.00 \mathrm{I}) \\
\text { Increased IS correlated with increased flow-mediated vasodilation, } \\
\mathrm{P}=0.00 \mathrm{I}\end{array}$ \\
\hline $\begin{array}{l}\text { Taubert } \\
\text { et al. }{ }^{10}\end{array}$ & $\begin{array}{l}\text { Single blind } \\
\text { crossover } \\
\mathrm{N}=44 \text {, ages } 56-73\end{array}$ & $\begin{array}{l}\text { Low habitual cocoa intake, BP, and } \\
\text { bioactive NO }\end{array}$ & $\begin{array}{l}\text { With DC: } \\
\text { Decreased systolic }(-2.9, \mathrm{p}>0.00 \mathrm{I}) \text { and diastolic BP }(-\mathrm{I} .9, \mathrm{p}<0.00 \mathrm{I}) \\
\text { Increased } \mathrm{NO} \text { expression by } 0.23 \mathrm{nmol} / \mathrm{L}(\mathrm{p}<0.00 \mathrm{I})\end{array}$ \\
\hline $\begin{array}{l}\text { Faridi } \\
\text { et al. }\end{array}$ & $\begin{array}{l}\text { Single blind } \\
\text { crossover } \\
N=45 \text {, mean age } 53\end{array}$ & $\begin{array}{l}\text { Cocoa consumption, } \mathrm{BP} \text {, and } \\
\text { endothelial function }\end{array}$ & $\begin{array}{l}\text { With DC: } \\
\text { Improved endothelial function (measured by } \mathrm{NO} \text { release: }+5.7+/-2.6 \%) \\
\text { Decreased systolic }(-3.2+/-5.8 \mathrm{mmHg}, \mathrm{P}<0.00 \mathrm{I}) \text { and diastolic }(-\mathrm{I} .4+/- \\
3.9 \mathrm{mmHg}, \mathrm{P}=0.0 \mathrm{I}) \mathrm{BP} \\
\text { With sugar-free } \mathrm{DC} \text { : } \\
\quad \text { Decreased systolic }(-2 . \mathrm{I}+/-7.0 \mathrm{mmHg}, \mathrm{P}<0.00 \mathrm{I}) \text { and diastolic } \\
\quad(-\mathrm{I} .2+/-8.7 \mathrm{mmHg}, \mathrm{P}<0.00 \mathrm{I}) \mathrm{BP}\end{array}$ \\
\hline
\end{tabular}

N, sample size; BP, blood pressure; DC, dark chocolate;WC, white chocolate; MI, myocardial infarction; IR, insulin resistance; IS, insulin sensitivity; NO, nitric oxide Summary Table

\section{Acknowledgements}

None.

\section{Conflict of interest}

The author declares no conflict of interest.

\section{References}

1. Centers of Disease Control and Prevention. Heart Disease and Stroke Prevention: Addressing the Nation's Leading Killers. 2011.

2. Hooper L, Kay C, Abdelhamid A, et al. Effects of chocolate, cocoa, and favan-3-ols on cardiovascular health: a systematic review and metaanalysis of randomized trials. Am J Clin Nutr. 2012;95(3):740-751. 
3. Corti R, Flammer A, Hollenberg N, et al. Cocoa and Cardiovascular Health. Circulation. 2009;119(10):1433-1441.

4. Shrime MG, Bauer SR, McDonald AC, et al. Flavanoid-Rich Cocoa Consumption Affects Multiple Cardiovascular Risk Factors in a MetaAnalysis of Short-Term Studies. J Nutr. 2011;141(11):1982-1988.

5. Keen CL, Holt RR, Oteiza PI, et al. Cocoa antioxidants and cardiovascular health. Am J Clin Nutr. 2005;81(1 Suppl):298S-303S.

6. Grassi D, Desideri G, Necozione S, et al. Blood Pressure is Reduced and Insulin Sensitivity Increased in Glucose-Intolerant, Hypertensive Subjects after 15 Days of Consuming High-Polyphenol Dark Chocolate. J Nutr. 2008;138(9):1671-1676.

7. Faridi Z, Njike V, Dutta S, et al. Acute dark chocolate and cocoa ingestion and endothelial function: a randomized controlled crossover trial. Am J Clin Nutr. 2008;88(1):58-63.
8. Grassi D, Lippi C, Necozione S, et al. Short-term administration of dark chocolate is followed by a significant increase in insulin sensitivity and a decrease in blood pressure in healthy persons. Am J Clin Nutr. 2005;81(3):611-614.

9. Grassi D, Necozione S, Lippi C, et al. Cocoa Reduces Blood Pressure and Insulin Resistance and Improves Endothelium-Dependent Vasodilation in Hypertensives. Hypertension. 2005;46(2):398-405.

10. Taubert D, Roesen R, Lehmann C, et al. Effects of Low Habitual Cocoa Intake on Blood Pressure and Bioactive Nitric Oxide. JAMA. 2007;298(1):49-60.

11. Buijsse B, Feskens E, Kok F, et al. Cocoa Intake, Blood Pressure, and Cardiovascular Mortality. Arch Intern Med. 2006;166(4):411-417.

12. Buijsse B, Weikert C, Drogan D, et al. Chocolate consumption in relation to blood pressure and risk of cardiovascular disease in German adults. Eur Heart J. 2010;31(13):1616-1623. 